\title{
Epidemiological Study on the Prevalence of Cigarette Smoking and Factors Associated with It among Nursing Students at Aliko Dangote College of Nursing Sciences Bauchi State, Nigeria
}

\author{
Ahmad Salisu Aliyu ${ }^{1^{*}}$, Nuru Yakubu Umar², Funmilayo Abubakar Sani ${ }^{2}$, Usman Uba \\ Abubakar ${ }^{3}$, Musa Alhaji Umar ${ }^{4}$ \\ ${ }^{I}$ Medical Laboratory Department Infectious Diseases Hospital (IDH) Kano, Nigeria \\ ${ }^{2}$ Aliko Dangote College of Nursing Sciences Bauchi State, Nigeria \\ ${ }^{3}$ College of Nursing Sciences, Abubakar Tafawa Balewa University Teaching Hospital Bauchi, Bauchi State, \\ Nigeria \\ ${ }^{4}$ Primary Health Care Development Agency Darazo Local Government Bauchi State, Nigeria
}

*Corresponding Author: Ahmad Salisu Aliyu, Medical Laboratory Department Infectious Diseases Hospital (IDH) Kano, Nigeria, Email: salisuahmadaliyu@yahoo.com

\begin{abstract}
Background: Smoking is currently considered one of the greatest problems in public health worldwide, and it is one of the most avoidable causes of death. The World Health Organization (WHO) attributes more than 4 million deaths a year to tobacco, and it is expected that this figure will rise to 10 million deaths a year by 2020.Every year 5,500 billion cigarettes are manufactured and 1.1 billion people smoke cigarette worldwide. Therefore, the aim of this study was to determine the prevalence of Cigarette smoking and factors associated with it among nursing students at Aliko Dangote College of Nursing Sciences Bauchi State, Nigeria.

Methods: Cross-sectional study design was conducted among nursing students at Aliko Dangote College of Nursing Sciences Bauchi State, Nigeria from February, 2020 to April, 2020. Data was collected using a pretested structured questionnaire. Descriptive analysis was performed to obtain the frequency distribution of the variables.
\end{abstract}

Results: The result shows that 300 participants responded to the questionnaire. The overall cigarette smoking prevalence was $4.7 \%$.

Conclusion: This study concluded that low proportion of nursing students at Aliko Dangote College of Nursing Sciences Bauchi State, Nigeria smoked cigarettes. Sex, age and peer influence were identified as important determinants of cigarette smoking. There is a need for early cost-effective interventions and education campaigns that target health science students.

Keywords: Bauchi, Cigarettes, Nursing, Smoking, Students, Tobacco

\section{INTRODUCTION}

Smoking remains the leading cause of preventable deaths, causing almost 6 million deaths globally every year [1]. Tobacco use is responsible for over 20 percent of all cancer deaths and 70 percent of all lung cancer deaths worldwide. It is also a risk factor for respiratory diseases (including asthma, bronchitis and emphysema) and cardiovascular diseases and stroke [2].

Despite all these, the number of smokers worldwide has now risen to about 1.3 billion and may well reach 1.5 billion by 2025 [3]. This increase in the consumption of tobacco is largely due to the targeting of young people and women by transnational tobacco companies.

In response, global public health organizations aim to provide consistent anti-smoking policies across the world $[4,5]$. However, to design appropriate scientifically-based policies to control the use of tobacco, there is a need to understand the patterns and social distribution of smoking [6]. 
Smoking is currently considered one of the greatest problems in public health worldwide, and it is one of the most preventable causes of death. Globally, the use and sale of substances such as alcohol and tobacco is causing substantial levels of health problems [7]. The World Health Organization (WHO) attributes more than 4 million deaths a year to tobacco and this figure is expected to increase to 10 million deaths a year by 2020. Moreover, it is now a growing public health challenge in the developing world [8]. According to WHO estimates, approximately $47 \%$ of men and $12 \%$ of women smoke cigarettes worldwide in 2010 [9]. Citing the death of 5 million individuals worldwide every year due to smoking-related diseases, the WHO states that smoking should be considered a pandemic [9]. In the United States, each year, approximately 440,000 persons die of diseases attributable to cigarette smoking leading to 5.6 million years of potential life lost, $\$ 82$ billion in lost productivity, and $\$ 75$ billion in direct medical costs [10]. Cigarette smoking has been described as a "gate way" substance towards illicit drug use among adolescents [11].

The onset of tobacco use occurs primarily in early adolescence, a developmental stage that is far removed by several decades from the death and disability that are associated with smoking in adulthood [12]. Therefore, the fact that many adult smokers initiated their smoking habit as adolescents makes adolescence smoking a significant public health problem [13]. It is also important as it is associated with respiratory health effects such as the incidence and exacerbation of asthma [14]. Studies showed that national smoking prevalence among men in sub-Sahara Africa varies from $20 \%$ to $60 \%$ and the annual cigarette consumption rates are on the rise for both men and women [13]. According to a report from Kenya, 7.2\% of schools going adolescents smoke cigarettes [13].

Accurate information on the prevalence, patterns and predictors of smoking in the world's poorest nations remains sparse [15]. For sub-Saharan Africa, in particular, a weak knowledge base limits the targeting of strategies to combat the potential growth of tobacco use and its harmful effect on future mortality. The strategies to combat the globalization of tobacco should be focused on better describing the extent and social distribution of the problem [16-18]. There is evidence that suggests that tobacco use is increasing in developing countries [19], and so surveillance of smoking prevalence can aid in developing locally grounded actions for tobacco control [1, 20]. This will prevent an escalation of tobacco use in these countries and therefore forestall the probable public health burden of smoking in the incoming years.

In Nigeria, not much is known about the sociodemographic dimensions of smoking from a national perspective, even though there are existing studies on tobacco use among various sub-population groups. Desalu et al. [21] carried out a study to determine the epidemiology of tobacco smoking in the adult population of northeastern Nigeria using a cross-sectional survey of 1793 adults in Yola. The prevalence of current smoking was $45.3 \%$ among males and $18.4 \%$ females, respectively. They conclude that the prevalence of tobacco smoking was very high in the study population.

Currently the prevalence of smoking is increasing at the global level and highly associated with increased rate of mortality and morbidity. It also results in reduction of quality of life, life expectance, low academic performance and increased costs on the smokers, increased risk of acquiring HIV/AIDS, mental problems, behavioral changes [ 22-24].

According to the study conducted in Jordan most of the smokers started smoking after the age of fifteen. Peer pressure was found to be the leading reason to be involved in smoking followed by seeking pleasure [25]. During the transition to higher learning institutions young adults face many new sources of stress including separation from family, sharing close living quarters with strangers, the formation of new social groups, intense academic pressures and the balancing of social engagements with academic and other life responsibilities which can lead them to get starting smoking [26]. Cigarette smoking gradually increased in the World because of its easy access at any place [27] and by the year 2025 there will be about 1.7 billion smokers across the globe [28]. According to study conducted at Haramaya University 225 $(22 \%)$ of the respondents smoked cigarettes at least once in their life time [29], at Aksum university $9.5 \%$ [30], at Calabar university Nigeria $55.8 \%$ of them smoke daily [31], in India $72.84 \%$ [32], in Rajasthan India 12.94\% were current smokers [33], at Hawassa university $14.8 \%$ have ever cigarette used in their life time [34]. 
Globally, tobacco use is a major cause of avoidable and premature mortality and morbidity, accounting for about 6 million deaths $[35,36]$. One person dies every six seconds due to tobacco related disease. Of these deaths, $75 \%$ occur in low and middle income countries where more than $80 \%$ of the world's smokers, including Nigeria's, live [35]. The death toll from tobacco is estimated to reach over 8 million deaths per year by 2030, and if unchecked, tobacco could kill over 1 billion people in the 21 st century $[37,38]$. It is estimated that 100 million premature deaths occurred globally in the $20^{\text {th }}$ century, due to tobacco smoking. Equally, tobacco smokers are believed to lose one decade of their life expectancy, when compared to people who have never smoked [35].

The Global Adult Tobacco Survey report for Nigeria shows that 4.5 million (5.6\%) adults aged 15 years or older currently smoke $(10.0 \%$ men and $1.1 \%$ women), while 6.4 million $(29.3 \%)$ of adults were exposed to second-hand smoke during visits to public places [39].

The Global Youth Tobacco Survey of Nigeria 2008 showed that one in five students aged 1315 years had ever experimented with cigarette smoking, and about one in ten students currently smoked cigarettes [40]. In a study among Pharmacy students in Lagos, Nigeria, the current smoking prevalence was low at 5.5\% [41]. In Nigeria, 7 in 10 current smokers planned to or were thinking about quitting; and 6 in 10 male smokers who visited a health care provider in the previous 12 months were advised to quit [39].

Several studies have documented that tobacco use and smoking are associated with some socio-demographic factors including; age, gender, marital status, education, employment, occupation, religion, ethnicity and place of residence (urban/rural) $[\mathbf{4 2}, \mathbf{4 3}]$.

A study in Nepal documented that the use of any form of tobacco was significantly associated with respondents' age, marital status, educational status, occupation, environment and watching television. The study found that; those aged 36-49 years were about 2 times more likely to use any form of tobacco than the younger age group 15-24 years; men married or in a relationship were about 2 times more likely to use tobacco. Men with no education (laborers) were about 4 times more likely than those that had education. However, watching television at least once weekly was found to reduce the risk of smoking [44].

Another study found that prevalence amongst men was significantly higher than in women for any type of tobacco use $(56.5 \%$ and $19.6 \%$, respectively), older adult, men, lesser education, and lower wealth quintile were more likely to use all forms of tobacco [43].

Similarly studies also reported that poor people are more likely to smoke more, less willing to quit smoking and more likely to die from smoking than people in the highest socioeconomic groups $[\mathbf{3 5}, \mathbf{3 7}, \mathbf{3 8}]$. The same trend is observed in initiation, as the likelihood that a young person will start smoking is higher in less privileged groups [43]. The identified rising social inequality of smoking and the associated health impacts were attributable to the age of initiation of smoking $[37,38,45]$.

Cigarette smoking is a very wide spread activity and consumption of cigarette has today reached the level of a global epidemic [46]. Every year 5,500 billion cigarettes are manufactured and 1.1 billion people smoke cigarette worldwide $[46,4]$.

In Nigeria, about 93 million sticks of cigarette are produced annually, with every one of these cigarette sticks being consumed [47]. Cigarette smoking has been found to be associated with heart and chronic obstructive lung diseases. Lung and other cancers (bladder, pancreas, upper respiratory tract, esophagus, stomach and leukemia) are increasingly being associated with cigarette smoking [46]. Millions of people suffer illness and disability due to cigarette smoking [4]. Cigarette smoking is associated with reduced life expectancy not only for active smokers but for passive smokers as well. Individuals 15-24 ages which are critical groups are mostly found in schools where they can be at the risk of developing smoking behaviors intentionally or unintentionally. Since they are going to be a productive age group major emphasize should be given to address this group.

However, the prevalence of cigarette smoking, especially among nursing students at Aliko Dangote College of Nursing Sciences Bauchi State, Nigeria is largely unknown and to the best of our knowledge, no student-based survey has been conducted on the prevalence of Cigarette smoking and its associated factors in Aliko Dangote College of Nursing Sciences Bauchi 
State, Nigeria. Therefore, the aim of this study was to determine the prevalence of Cigarette smoking and factors associated with it among nursing students at Aliko Dangote College of Nursing Sciences Bauchi State, Nigeria.

\section{Methodology}

\subsection{Study Area and Study Design}

The study was conducted at Aliko Dangote College of Nursing Sciences Bauchi State, Nigeria. A cross- sectional study was conducted using interviewer-administered questionnaire from February, 2020 to April, 2020.

\subsection{Sample Size Determination}

In this study, manual calculation of the sample size using Morgan and Krejcie (1970) formula was used for sample size determination as stated below:

$\mathrm{S}=\mathrm{X}^{2} \mathrm{NP}(1-\mathrm{P}) \div \mathrm{d}^{2}(\mathrm{~N}-1)+\mathrm{X}^{2} \mathrm{P}(1-\mathrm{P})$

Where:

$\mathrm{S}=$ Required sample size

$\mathrm{X}^{2}=$ The table value of the chi-square at desired confidence (3.841)

$\mathrm{N}=$ Study Population size (1367)

$\mathrm{P}=$ Population proportion assumed to be 0.50 since this would provide maximum sample size

$\mathrm{d}^{2}=$ Degree of accuracy of the result expressed as proportion 0.050

$3.841 \times 1367 \times 0.5 \times 0.5$

$0.0025 \times 1366+3.841 \times 0.5 \times 0.5$

$$
\underline{1312.66175}=300
$$

4.37525

Hence 300 respondents

\subsection{Inclusion and Exclusion Criteria}

Table1: Socio demographic characteristics of respondents $(n=300)$

\begin{tabular}{|l|l|l|}
\hline \multicolumn{1}{|c|}{ Characteristics } & \multicolumn{1}{c|}{ Frequencies } & \multicolumn{1}{c|}{ Percentages \% } \\
\hline Gender & & 85 \\
\hline Males & 255 & 15 \\
\hline Females & 45 & \\
\hline Ages & & 41.7 \\
\hline $20-25$ & 125 & 33.3 \\
\hline $26-30$ & 100 & 18.3 \\
\hline $31-35$ & 55 & 6.7 \\
\hline $36+$ & 20 & \\
\hline Marital status & & 35 \\
\hline Married & 105 & 46.7 \\
\hline Single & 140 & \\
\hline
\end{tabular}

Students who were on training at least for 6 month in the study area were included and Students who were on training, critically sick during data collection were excluded from the study.

\subsection{Data Collection}

Data was collected from eligible and willing participants using a pre-tested, structured questionnaire. Socio-demographic information including age, gender, and marital status, year of study and socio economic status was collected.

\subsection{Data Analysis}

Data were analyzed using Statistical Package for Social Science (SPSS) software version 16.0 at that time with the help of the Statistician. The descriptive statistical method was used to analyze frequencies and percentages.

\subsection{Ethical Considerations}

This study was conducted only After getting Approval from Ministry of Health Bauchi State, data collectors was informed about the study, then after Verbal and written Informed consent obtained from study subjects, Confidentiality was assured for all the information provided, no personal identifiers (anonymity) was used on the questionnaires.

\section{RESUltS}

\subsection{Socio-Demographic Characteristics}

A total of 300 respondents were interviewed, giving $100 \%$ response rate. Majority of respondents 255, (85\%) were males. Among all, $125(41.7 \%)$ of respondents were $20-25$ years of age. Of the study subjects, $140(46.7 \%)$, were single, 105 (35\%), were married. The vast majority $125(41.7 \%)$ of respondents were in first year of study, 118(39.3\%) were in second year of study and 57 (19\%) were in third year of study (Table 1). 
Epidemiological Study on the Prevalence of Cigarette Smoking and Factors Associated with It among Nursing Students at Aliko Dangote College of Nursing Sciences Bauchi State, Nigeria

\begin{tabular}{|c|c|c|}
\hline Divorced & 15 & 5 \\
\hline Widowed & 40 & 13.3 \\
\hline \multicolumn{3}{|c|}{ Year of Study } \\
\hline First year & 125 & 41.7 \\
\hline Second year & 118 & 39.3 \\
\hline Third year & 57 & 19 \\
\hline \multicolumn{2}{|c|}{$\begin{array}{l}\text { From } 300 \text { study participants } 115(38.3 \%) \text { had } \\
\text { ever smoked cigarette, fourteen respondents } \\
(4.7 \%) \text { were current cigarette smokers; however, } \\
19(6.3 \%) \text { of the respondents bought cigarette in } \\
\text { the past } 30 \text { days. } 18 \text { ( } 6 \%) \text { would allow cigarette } \\
\text { smokers to smoke in their homes and majority } \\
\text { of the respondents } 279(93 \%) \text { have a friends } \\
\text { who smokes cigarette. Eighty seven ( } 29 \%) \text { of } \\
\text { the respondents smoked in the presence of non- } \\
\text { smokers, although } 245(81.7 \%) \text { of them had }\end{array}$} & $\begin{array}{l}\text { respondents wish to stop smoking. } 228(76 \%) \text { of } \\
\text { the respondents live with peoples who smokes } \\
\text { cigarette. Majority of the respondents } 282(94 \%) \\
\text { spent }>20 \text { Naira on cigarette smoking. Only } 14 \\
(4.7 \%) \text { agree with smoking behaviour, } 26 \\
(8.7 \%) \text { would allow smoking in household and } \\
\text { majority } 295(98.3 \%) \text { agree with banning } \\
\text { smoking in public areas. All the respondents } \\
300(100 \%) \text { would not allow children to smoke } \\
\text { in the future }\end{array}$ \\
\hline
\end{tabular}
ever tried stopping to smoke. 248 (82.7\%)

Table2: Prevalence and Practices of Cigarette smoking among respondents $(n=300)$

\begin{tabular}{|l|l|l|}
\hline \multicolumn{1}{|c|}{ Characteristics } & Frequencies & Percentages \% \\
\hline Have you ever smoked cigarette & 115 & \\
\hline Yes & 185 & 38.3 \\
\hline No & & 61.7 \\
\hline Have you ever tried smoking? & 125 & \\
\hline Yes & 175 & 41.7 \\
\hline No & & 58.3 \\
\hline Do you currently smoke? & 14 & \\
\hline Yes & 286 & 4.7 \\
\hline No & & 95.3 \\
\hline Do you allow cigarette smokers to smoke in your home? & 18 & \\
\hline Yes & 282 & 6 \\
\hline No & & 94 \\
\hline Have you smoked cigarette in the past 30 days? & 25 & \\
\hline Yes & 275 & 8.3 \\
\hline No & & 91.7 \\
\hline Have you bought cigarette in the past 30 days? & 19 & \\
\hline Yes & 281 & 6.3 \\
\hline No & & 93.7 \\
\hline Do you smoke in the presences of none smokers? & 87 & \\
\hline Yes & 213 & 29 \\
\hline No & & 71 \\
\hline Have you ever tried to stop smoking? & 245 & \\
\hline Yes & 55 & 81.7 \\
\hline No & & 18.3 \\
\hline Do you want to stop smoking now? & 248 & \\
\hline Yes & 52 & 82.7 \\
\hline No & & 17.3 \\
\hline Do you have a friend who smokes cigarette? & 279 & \\
\hline Yes & 21 & 93 \\
\hline No & & 7 \\
\hline Do you live with peoples who smokes cigarette? & 228 & \\
\hline Yes & 72 & 76 \\
\hline No & 18 & 94 \\
\hline How much you spent on cigarette? & 282 & 95.3 \\
\hline $10-20$ Naira & 14 & \\
\hline$>20$ Naira & 286 & \\
\hline Do you agree with smoking behaviour? & & \\
\hline Yes & & \\
\hline No & & \\
\hline & & \\
\hline
\end{tabular}


Epidemiological Study on the Prevalence of Cigarette Smoking and Factors Associated with It among Nursing Students at Aliko Dangote College of Nursing Sciences Bauchi State, Nigeria

\begin{tabular}{|l|l|l|}
\hline Would you allow smoking in your household? & & \\
\hline Yes & 26 & 8.7 \\
\hline No & 274 & 91.3 \\
\hline Would you allow your children to Smoke in the future? & & \\
\hline Yes & 0 & 0 \\
\hline No & 300 & 100 \\
\hline Do you agree with banning smoking in public areas? & & \\
\hline Yes & 295 & 98.3 \\
\hline No & 5 & 1.7 \\
\hline
\end{tabular}

Majority of the respondents 120 (40\%), 110 $(36.7 \%)$ mention that recreation and peer pressure as a reason why students smoke. Majority of the respondents knew that cigarette smoking could lead to lung cancer 298 (99.3\%) and heart diseases 289 (96.3\%). Majority of the respondents knew that cigarette smoking could lead to peptic ulcer disease (PUD) 278 (92.7\%). However, majority of the respondents 269 $(89.7 \%)$ knew that inhaling smoke from another person's cigarette could lead to lung disease. $298(99.3 \%)$ of the respondents answer that they have an official policy banning smoking in

Table3: Knowledge of Respondents towards Cigarette Smoking ( $n=300$ )

\begin{tabular}{|l|l|l|}
\hline \multicolumn{1}{|c|}{ Characteristics } & Frequencies & \multicolumn{1}{|c|}{ Percentages \% } \\
\hline Why do students smoke? & 120 & 40 \\
\hline Recreation & 55 & 18.3 \\
\hline Proving manhood & 110 & 36.7 \\
\hline Peer pressure & 15 & 5 \\
\hline Other reasons & & \\
\hline cigarette smoking lead to lung disease & 298 & 99.3 \\
\hline Yes & 2 & 0.7 \\
\hline No & & \\
\hline cigarette smoking lead to heart disease & 289 & 96.3 \\
\hline Yes & 11 & 3.7 \\
\hline No & & \\
\hline cigarette smoking lead to peptic ulcer disease & 278 & 92.7 \\
\hline Yes & 22 & 7.3 \\
\hline No & & \\
\hline inhaling smoke from another person's cigarette lead to lung disease & 269 & 89.7 \\
\hline Yes & 31 & 10.3 \\
\hline No & & \\
\hline $\begin{array}{l}\text { Does your school have an official policy banning smoking in school } \\
\text { buildings? }\end{array}$ & 298 & 99.3 \\
\hline Yes & 2 & 0.7 \\
\hline No & & \\
\hline During classes, were you taught about the dangers of smoking? & 300 & 100 \\
\hline Yes & 0 & 0 \\
\hline No & & \\
\hline $\begin{array}{l}\text { During classes, were you taught about the reasons why people } \\
\text { smoke? }\end{array}$ & 266 & 88.7 \\
\hline Yes & 34 & 11.3 \\
\hline No & & \\
\hline Did you learn that it is important to record tobacco use history? & 292 & 97.3 \\
\hline Yes & 8 & 2.7 \\
\hline No & & \\
\hline $\begin{array}{l}\text { Did you learn that it is important to provide educational quitting } \\
\text { materials? }\end{array}$ & 286 & 95.3 \\
\hline Yes & & \\
\hline & & \\
\hline
\end{tabular}


Epidemiological Study on the Prevalence of Cigarette Smoking and Factors Associated with It among Nursing Students at Aliko Dangote College of Nursing Sciences Bauchi State, Nigeria

\begin{tabular}{|l|l|l|}
\hline No & 14 & 4.7 \\
\hline Have you ever heard of nicotine replacement therapies? & & \\
\hline Yes & 273 & 91 \\
\hline No & 27 & 9 \\
\hline Have you heard of antidepressant use in cessation programmed? & & \\
\hline Yes & 259 & 86.3 \\
\hline No & 41 & 13.7 \\
\hline
\end{tabular}

\section{DISCUSSION}

In this study, the percentage of the prevalence of smoking among nursing students in Aliko Dangote College of Nursing Sciences Bauchi State, Nigeria was found to be $4.7 \%$. The prevalence rate was lower compared with the results from similar studies in Arab countries conducted among health-related students, including $46 \%$ in Kuwait [48], $17.2 \%$ in Jordan [49], 46.7\% in Egypt [50] and $26.3 \%$ in Lebanon [51]. However On the other hand, this prevalence was also lower than the prevalence rate in some equivalent studies conducted on ages ranging from 18 to 28 years in Iran $(9.8 \%)$ [52]. Even though smoking prevalence might be fairly low which is good from public health's perspective, the number of smokers and tobacco use may actually be large considering the entire population of the country. According to Pampel, 2008 Nigeria had the largest number of smokers and yet among the countries with the lowest smoking prevalence of the 14 countries included in his study. At the other extreme, Namibia had the largest smoking prevalence among these studied countries which only amounted to 114,000 smokers. Smoking prevalence increases with age up to a point and then it falls.

In the current study, the prevalence rate of smoking was significantly affected by family income, that is, the percentage of smokers among students from low income families was higher than those from average and high income ones, this finding was found to be in conformity with the world health survey, which stated that the poorest men were over 2.5 times more likely to smoke than the richest men in numerous countries [53]. A possible reason also could be that students with a lower socio-economic status had more physical, psychosocial and emotional problems.

Peer pressure and recreation were found to be the main reasons for students becoming involved in smoking, while 'proving manhood' was a major reason for non-smokers' attitudes, according to this study; similar findings were reported by previous studies [54]. 38.3\% respondents in this study have ever smoked cigarette. This is higher than $20.5 \%$ reported by Adebiyi in Oyo state, Southwestern Nigeria and lower than $46 \%$ reported by Odukoya in Lagos state in the same region $[\mathbf{5 5}, \mathbf{5 6}]$.

In this study, one of the predictors of cigarette smoking was sex whereby more percentage of males smoked cigarettes than females. According to a study in Jakarta (Indonesia), Guangdong (China) and Nepal, male predominance was reported in the habit of smoking, while in Zambia [57], in the Indian cities of Delhi and Goa, and in the Czech Republic, no gender differences have been observed [58]. Smoking is found to be strongly associated with male sex in almost all populations in studies conducted in Africa [5964]. This may be because females are more socially restricted than male counter parts and mostly young people imitate and exercise what they observe from their elders, parents and friends. Furthermore, familial relationships including care and family related activities may protect females from involving in tobacco use [65].

Many of the respondents were knowledgeable about some aspects of the health risks associated with tobacco use. Student's cigarette smoking was significantly associated to year of study. Accordingly, as the year the students spent within the college increases, for instance from second year to third year according to our study, the prevalence of cigarette smoking is increasing. For this peer pressure, need to get relaxed from tension and aim to improve results than the previous semesters were the possible reasons for the increment. Most students also imitate what their seniors doing as if it is an indication of modernization.

\section{CONCLuSiON}

This study concluded that low proportion of nursing students at Aliko Dangote College of Nursing Sciences Bauchi State, Nigeria smoked cigarettes. Sex, age and peer influence were identified as important determinants of cigarette smoking. There is a need for early 
cost-effective interventions and education campaigns that target health science students.

\section{ACKNOWLEDGMENTS}

I am grateful to thank the study participants and acknowledge the team of research assistants.

\section{REFERENCES}

[1] World Health Organization (1997): Tobacco or health: A global status report.

[2] Lim SS, Vos T, Flaxman AD, Danaei G, Shibuya K, Adair-Rohani H, et al. (2013) A comparative risk assessment of burden of disease and injury attributable to 67 risk factors and risk factor clusters in 21 regions, 19902010: A systematic analysis for the Global Burden of Disease Study (2010) . The Lancet 380(9859):2224-60.

[3] Mackay J, Eriksen M, Shafey O (2006). The tobacco atlas. American Cancer Society. Atlanta, Georgia, USA; (2006).

[4] World Health Organization (2008): report on the global tobacco epidemic, (2008) -the MPOWER package. Geneva, Switzerland.

[5] World Health Organization (2015): report on the global tobacco epidemic, 2015: Raising taxes on tobacco; 2015.

[6] Kaleta D, Makowiec Dąbrowska T, Dziankowska Zaborszczyk E, Fronczak A. (2012) Prevalence and socio-demographic correlates of daily cigarette smoking in Poland: Results from the Global Adult Tobacco Survey (2009-2010). International Journal of Occupational Medicine and Environmental Health 25(2): 126-36.

[7] Weiss MG, Cohen A, Eisenberg L (2001) Mental health. In International public health. Edited by Merson MH, Black RE, Mills AJ. Maryland: Aspen Publishers 331-378.

[8] Peto R, Lopez AD, Boreham J, Thun M, Heath C: (1994) Mortality from smoking in developed countries (1950-2000) ; indirect estimation from National Vital Statistics. Oxford: Oxford University Press.

[9] Tobacco free initiative (TFI): (2005) Why is tobacco a public health priority? http://www. who.int/ tobacco/health_priority/en.

[10] Center for Disease Control (2002): Annual smoking-attributable mortality, years of potential life lost, and economic costs - United States, (1995-1999). MMWR (2002), 51:300-303.

[11] Gilliland FD, Islam T, Berhane K, Guaderman WJ, McConnoll R, Avol E, Peters JM (2006) : Regular smoking and asthma incidence in adolescents. Am J Respir Cirt Care Med (2006), 174:1094-1100.

[12] Elders MJ, Perry CL, Eriksen MP, GA G (1994) The report of the Surgeon General: preventing tobacco use among young people. Am J Public Health 1994, 84(4):543-547.

[13] Warren CW, Jones NR, Peruga A, Chauvin J, Baptiste J-P, de Silva VC, el Awa F, Tsouros A, Rahman K, Fishburn B, et al: (2008) Global Youth Tobacco Surveillance, (2000-2007) . MMWR 57(SS01):1-21.

[14] Rudatsikira E, Muula AS, Siziya S: (2009) Current cigarette smoking among in-school American youth: results from the (2004) national youth tobacco surveillance. International J Equity: Health 8(10).

[15] Pampel F. (2008) Tobacco use in sub-Sahara Africa: Estimates from the demographic health surveys. Social Science \& Medicine 66(8) : 1772-83.

[16] Corrao MA, Guindon GE, Cokkinides V, Sharma N. (2000) Building the evidence base for global tobacco control. Bulletin of the World Health Organization. 2000; 78(7): 88490.

[17] Jha P, Ranson MK, Nguyen SN, Yach D. (2002) Estimates of global and regional smoking prevalence in 1995 , by age and sex. American Journal of Public Health 92(6):1002-6.

[18] World Health Organization (2009): report on the global tobacco epidemic, (2009): implementing smoke-free environments.

[19] Lopez AD, Mathers CD. (2006) Measuring the global burden of disease and epidemiological transitions: (2002-2030). Annals of Tropical Medicine and Parasitology. 100(5-6):481-99.

[20] Lando HA, Borrelli B, Klein LC, Waverley LP, Stillman FA, Kassel JD, et al. (2005) The landscape in global tobacco control research: A guide to gaining a foothold. American Journal of Public Health 95(6):939-45.

[21] Desalu O, Olokoba A, Danburam A, Salawu F, Issa B (2008) Epidemiology of tobacco smoking among adults population in northeast Nigeria. The Internet Journal of Epidemiology 6(1).

[22] Bronnum H, Juel K (2001). Abstention from smoking extends life and compresses morbidity: a population based study of health expectancy among smokers and non-smokers in Denmark. Tobacco control 10:237-78.

[23] Louie D (2001). The effects of cigarette smoking on cardiopulmonary function and exercise tolerance in teenagers. Canadian respiratory journal 8:289-91.

[24] Yousafzai AW, Ahmer S, Syed E, Bhutto N, Iqbal S, Siddiqi MN, Zaman M (2009): Wellbeing of medical students and their awareness on substance misuse: a cross-sectional survey in Pakistan. Annals of General Psychiatry, v 8:8.

[25] Khader Y.S, Alsadi A.A (2008). Smoking habits among university students in Jordan: 
prevalence and associated factors, Eastern Mediterranean Health Journal, Vol. 14, No. 4.

[26] Joseph A (2003): Depression, Substances Abuse and College Student Engagement: A Review of the Literature.

[27] Attila, S. M.; Tufan, N. Baştaş, S (2007). Attitudes towards smoking and frequency of smoking among students of Duzce medical school. TAF Prev. Med. Bull., 6, 364-370.

[28] World Health Organization (2004). Tobacco Free Initiative. Building Blocks for Tobacco Control: A Handbook; WHO: Geneva, Switzerland,; pp. 4-13.

[29] Gezahegn T, Andualem D, and Mitiku T (2014). Substance Use and Associated Factors among University Students in Ethiopia: A Cross-Sectional Study, Journal of Addiction.

[30] Measho G, Amsalu F, Tesfahun M (2013). Psychoactive substances use and associated factors among Axum university students, Axum Town, North Ethiopia, BMC Public Health, 13:693.

[31] Joseph K. Ukwayi, Ojong F, Chibuzo C (2012). Peer Pressure and Tobacco Smoking among Undergraduate Students of the University of Calabar, Cross River State, Higher Education Studies; Vol. 2, No. 3.

[32] Gouri K, Sangeeta D, Trilochan S, Sourajit P (2014). Prevalence and Causes of Substance Abuse among Undergraduate Medical College Students, Indian Medical Gazette.

[33] Jai Prakash P, Madan S, Pankaj S, Anjali M (2015). Prevalence and Associated Factors of Tobacco Smoking among Undergraduate Medical and Dental Students in Rajasthan, International Journal of Scientific Study, Vol 3, Issue 4.

[34] Andargachew K, Serawit D (2014). Prevalence and Determinants of Active and Passive Cigarette Smoking among undergraduate students at Hawassa University, Hawassa, Ethiopia, Journal of Tropical Diseases and Public Health, Volume 2, Issue 4.

[35] World Health Organization (2013): Tobacco Fact Sheet www.who.int/mediacentre/fact sheets/fs339/en/. Published, (2013). Accessed February 15, (2017).

[36] Eriksen M, Mackay J, Ross H (2017). The Tobacco Atlas. 4th ed. Atlanta, Georgia, USA: American Cancer Society; (2012). Accessed February 15, 2017.

[37] Mathers CD, Loncar D. (2006) Projections of global mortality and burden of disease from (2002) to (2030). PloS Medicine. 3(11):e442. doi:10.1371/journal.pmed.0030442.

[38] Peto R, Lopez AD, Boreham J, Thun M, Heath C: (1994) Mortality from smoking in developed countries (1950-2000) ; indirect estimation from National Vital Statistics. Oxford: Oxford University Press.

[39] Global Adult Tobacco Survey: (2012) Country Report. World Health Organization. https://www.who.int/ tobacco/surveillance/survey/gats/nigeria_countr y_report.pdf. Accessed February 15, (2017).

[40] Ekanem IA, Asuzu MC, Anunobi CC, Malami SA, Jibrin PG, Ekanem AD, et al. (2010) Prevalence of tobacco use among youths in five centres in Nigeria: A Global Youth Tobacco Survey (GYTS) approach. Journal of Community Medicine and Primary Health Care 22(1/2):62-67. doi:10.4314/jcmphc.v22i12.68336 .

[41] Khanal V, Adhikari M, Karki S. (2013) Social determinants of tobacco consumption among Nepalese men: findings from Nepal Demographic and Health Survey (2011). Harm Reduction Journal 10(40). Doi: 10.1186/14777517-10-40.

[42] World Health Organization (2015): report on the global tobacco epidemic, 2015: Raising taxes on tobacco; 2015.

[43] World Health Organization (2012): A Comprehensive Global Monitoring Framework Including Indicators and a Set of Voluntary Global Targets for the Prevention and Control of Non-communicable Diseases. World Health Organization. https://www.who.int/nmh/events /2011/.../WHO_Discussion_Paper_FINAL.pdf. Published, 2012. Accessed February 15, 2017.

[44] Action on Smoking and Health (2009): Fact Sheet What's In a Cigarette. http://ash.org.uk/ information-andresources/fact-sheets/whats-ina-cigarette. Published, (2009). Accessed February 15, (2017).

[45] Centre for Disease Control and Prevention (2012) A Report of the Surgeon General 2012: Preventing Tobacco Use among Youths and Adults.

https://www.cdc.gov/tobacco/data_statistics/sgr /2012/.../ consumer.pdf. Published, 2012. Accessed February 15, 2017.

[46] Can G, Topbas M, Oztuna F, Ozgun S, Can E (2009) Factors contributing to regular smoking in adolescents in Turkey. J School Health 79: 93-97.

[47] Obinna C (2011) Nigeria tobacco control bill.

[48] Husain H, Al-Fadhli F, Al-Olaimi F, et al. (2016) Is smoking shisha safer than cigarettes: comparison of health effects of shisha and cigarette smoking among young adults in Kuwait. Medical Principles and Practice 25(2):117-122. doi:10.1159/000442417.

[49] Alomari Q, Barrieshi-Nusair K, Said K. (2006) Smoking prevalence and its effect on dental health attitudes and behavior among dental 
students. Medical Principles and Practice. 15(3):195 199. Doi: 10.1159/000092181.

[50] Khan AA, Dey S, Taha AH, et al. (2012) Attitudes of Cairo University medical students toward smoking: the need for tobacco control programs in medical education. The Journal of the Egyptian Public Health Association. 87:1. doi:10.1097/01.epx.0000411467.14763.0b.

[51] Jradi H, Wewers ME, Pirie PR, Binkley PF, Ferketich K. (2013) Cigarette and waterpipe smoking associated knowledge and behaviour among medical students in Lebanon. Eastern Mediterranean Health Journal 19:861- 868. doi:10.26719/2013.19.10.861.

[52] Taheri E, Ghorbani A, Salehi M, Sadeghnia HR (2015) Cigarette Smoking Behavior and the Related Factors Among the Students of Mashhad University of Medical Sciences in Iran. Iranian Red Crescent Medical Journal 17(1). doi:10.5812/ircmj.16254.

[53] Hosseinpoor A.R., Parker L.A., Tursan d'Espaignet E., Chatterji S. (2012) Socioeconomic inequality in smoking in lowincome and middle-income countries: Results from the World Health Survey. PloS one. 2012 Aug 29; 7(8):e4284.

[54] Musmar S.G. (2012) Smoking habits and attitudes among university students in Palestine: a cross-sectional study. Eastern Mediterranean Health Journal 18(5):454.doi:10.26719/2012.18.5.454.

[55] Adebiyi AO, Faseru B, Sangowawa AO, Owoaje ET (2010) Tobacco use amongst out of school adolescents in a local Government area in Nigeria. Subst Abuse Treat Prev Policy 5: 24.

[56] Odukoya OO, Dada MR, Olubodun T, Igwilo UA, Ayo-Yusuf OA (2016) Risk perception and correlates of tobacco use among young people outside of formal school settings in Lagos state, Nigeria. Asian Pac J Cancer Prev 17: 2833-2839.
[57] Siziya S, Rudatsikira E, Muula AS, Ntata PR: (2007) Predictors of cigarette smoking among adolescents in rural Zambia: results from a cross sectional study from Chongwe district. Rural Rem Health 7(3):728-732.

[58] Global Youth Tobacco Survey Collaborating Group: (2003) Differences in worldwide tobacco use by gender: findings from the Global Youth Tobacco Survey. J Sch Health 73:207-215.

[59] Schoemaker N, Hermanides J, Davey G: (2005) Prevalence and predictors of smoking in Butajira town, Ethiopia, 2003. Ethiop J Health Dev 2005, 19(3):182-187.

[60] Rudatsikira E, Abdo A, Muula AS: (2007) Prevalence and determinants of adolescent tobacco smoking in Addis Ababa, Ethiopia. BMC Publ Health 7(176):1-6.

[61] Steyn K, Bradshaw D, Norman R, Laubscher R, Saloojee Y: (2002) Tobacco use in South Africans during 1998: the first demographic and health survey. J Cardiovasc Risk 9:161-170.

[62] Idris AM, Ibrahim YE, Warnakulasuriya KA, Cooper DJ, Johnson P, Nilsen R: (1998) Toombak use and cigarette smoking in the Sudan: estimates of prevalence in the Nile state. Prev Med 27:597-603.

[63] Jagoe K, Edwards R, Mugusi F, Whiting D, Unwin N: (2002) Tobacco smoking in Tanzania, East Africa: population based smoking prevalence using expired alveolar carbon monoxide validation tool. Tob Cont 11:210-214.

[64] Rudatsikira E, Dondog J, Siziya S, Muula AS: (2008) Prevalence and determinants of adolescent cigarette smoking in Mongolia. Singapore Med J 49(1):57-62.

[65] Van den Bree MB, Whitmer MD, Pickworth WB: (2004) Predictors of smoking development in a population-based sample of adolescents: a prospective study. J Adolesc Health 35(3):172 181.

Citation: Ahmad Salisu Aliyu, et.al, Epidemiological Study on the Prevalence of Cigarette Smoking and Factors Associated with It among Nursing Students at Aliko Dangote College of Nursing Sciences Bauchi State, Nigeria.ARC Journal of Public Health and Community Medicine. 2020; 5(4):8-17. Doi:doi.org/10.2043 1/2456-0596.0504002.

Copyright: (c) 2020 Authors. This is an open-access article distributed under the terms of the Creative Commons Attribution License, which permits unrestricted use, distribution, and reproduction in any medium, provided the original author and source are credited. 